\title{
Linking emotion recognition and income: An examination of the interpersonal mechanisms
}

Wihler, Andreas ; Momm, Tassilo ; Menges, Jochen ; Blickle, Gerhard

\begin{abstract}
The article presents research on the association of emotion recognition with annual income through interpersonal mechanisms in work environment. The study shows workplace success bearing upon and integrating social influence research and emotional abilities. It recommends people with having higher emotion recognition ability (ERA) levels get higher annual income as they have better political skills allowing them to smoothly operate on an interpersonal level. The significant factor of job performance, which serve as mediators between annual income and ERA is proposed.
\end{abstract}

DOI: https://doi.org/10.5465/AMBPP.2014.72

Posted at the Zurich Open Repository and Archive, University of Zurich

ZORA URL: https://doi.org/10.5167/uzh-172576

Conference or Workshop Item

Published Version

Originally published at:

Wihler, Andreas; Momm, Tassilo; Menges, Jochen; Blickle, Gerhard (2014). Linking emotion recognition and income: An examination of the interpersonal mechanisms. In: 2014 Annual Meeting of the Academy of Management, Philadelphia, Pennsylvania, 1 August 2014 - 5 August 2014, Academy of Management.

DOI: https://doi.org/10.5465/AMBPP.2014.72 
Wihler, A., Momm, T. D., Menges, J., \& Blickle, G. (2014). Linking Emotion Recognition and Income: An Examination of the Interpersonal Mechanisms. Academy of Management Annual Meeting, August 1-5, in Philadelphia, PA, US

From this paper emerged the following papers

Wihler, A., Momm, T., Menges, Jochen I. \& Blickle, G. (2014). Linking Emotion Recognition and Income: An Examination of the Interpersonal Mechanisms. Academy of Management Proceedings, 2014: 1 13314. Doi: 10.5465/AMBPP.2014.72

And

Momm, T. D., Blickle, G., Liu, Y., Wihler, A., Kholin, M., \& Menges, J. (2015). It pays to have an eye for emotions: Emotion recognition ability indirectly predicts annual income. Journal of Organizational Behavior, 36, 147-163 DOI: 10.1002/job.1975 


\title{
LINKING EMOTION RECOGNITION AND INCOME:
}

\section{AN EXAMINATION OF THE INTERPERSONAL MECHANISMS}

\begin{abstract}
This study integrates the emotion and social influence literatures to examine how emotion recognition ability (ERA) facilitates performance and increases income through political skill. In a sample of 142 employee-peer-supervisor triads from a broad range of jobs and organizations, we find that people's level of ERA relates to how much they earn. The relationship between ERA and annual income is mediated sequentially through political skill and interpersonal facilitation. The results imply that emotional abilities allow people not only to process affect-laden information effectively, but also to use this information to successfully navigate the social world of organizations in the pursuit of high performance and high income.
\end{abstract}

\section{Keywords:}

emotion recognition ability, political skill, performance, income 


\section{LINKING EMOTION RECOGNITION AND INCOME:}

\section{AN EXAMINATION OF THE INTERPERSONAL MECHANISMS}

An enduring question in organizational science is what makes people successful at work. Recent research offers new answers that point to emotional intelligence (Joseph \& Newman, 2011; Mayer \& Salovey, 1997) and, more specifically, to people's emotion recognition ability (ERA) - a specific ability that involves the detection, extraction, and deciphering of emotional information from facial and vocal expressions (Elfenbein, Marsh, \& Ambady, 2002). Indeed, those able to accurately recognize emotions in others tend to be better at building and maintaining relationships and are more likely to be successful in some areas of work and life (e.g., Nowicki \& Duke, 1994; Rosenthal, Hall, DiMatteo, Rogers, \& Archer, 1979; for a review see Elfenbein, Foo, White, Tan, \& Aik, 2007). What has remained unclear, however, is why there is a link between the basic ability to recognize emotions in others and success (Elfenbein, Foo et al., 2007) and whether this link extends to job performance and objective career-related outcomes.

In an endeavor to map out and test the mechanisms that explain the relationships between ERA and work outcomes, we advance an integration of two previously separate literatures, the emotion and the social influence literatures. Specifically, we suggest that the consideration of a set of interpersonal skills well-known in the social influence literature as political skill helps unlock the black box of the ERA - performance relationship. Political skill is defined as "the ability to effectively understand others at work and to use such knowledge to influence others to act in ways that enhance one's personal and/or organizational objectives" (Ferris, Treadway et al., 2005, p. 127). Here we suggest that ERA serves as a fundamental ability that allows people to effectively apply political skill in order to perform at higher levels at work and to enhance their income. Thus we extend ERA research by examining how employees' ERA, through their 
political skill, affects a specific aspect of how well they perform on their job (i.e., interpersonal facilitation) and, in turn, their annual income.

Thus this study puts forth a model of workplace success that bears upon and integrates emotional abilities and social influence research. To preview our theoretical model, we suggest that people with higher levels of ERA receive a higher annual income because these people tend to have better political skills that allow them to operate more smoothly on an interpersonal level. Technically speaking, we propose a multiple mediation model depicted in Figure 1 in which political skill and an important aspect of job performance (i.e., interpersonal facilitation) sequentially serve as mediators between ERA and annual income. Our research builds upon previous work that noted the potential linkages between emotional abilities, political skill, and performance (e.g., Ferris, Hochwarter, Douglas, Blass, Kolodinsky, \& Treadway, 2002; Liu, Ferris, Treadway, Prati, Hochwarter, \& Perrewé, 2006) and responds to recent calls for research on the intermediate linkages between ERA and performance (Elfenbein, Foo, White, Tan, and Aik, 2007).

*** Insert Figure 1 about here $* * *$

\section{LINKING EMOTION RECOGNITION ABILITY AND PERFORMANCE THROUGH POLITICAL SKILL}

\section{The Social Influence Perspective of Organizations}

Organizations represent social systems in which members must both compete with each other for limited resources and cooperate in order to facilitate access to these resources and get things done (Burns, 1962). Effectiveness in organizations involves proactively balancing the power relationships between oneself and others (Emerson, 1962), and successfully navigating the social environment at work (Minzberg, 1983; Pfeffer, 1981), including building strong social networks infused with rapport and trust (Ferris et al., 2005; Seibert, Kraimer, \& Liden, 2001). 
The social influence perspective suggests that influence, politics, networking, and interpersonal competencies are intricately interwoven to affect performance and effectiveness in organizations (e.g., Mintzberg, 1983; Pfeffer, 1981, 2010; Ferris et al., 2005; Ferris \& Hochwater, 2011).

The significance of building connections at work has become even stronger with recent changes in the competitive dynamics of global markets that promote a more social, interactive work environment (Cascio, 1995; Daft \& Lewin, 1993). Today, “jobs” are no longer viewed as a static set of tasks, duties, and responsibilities, but rather as fluid, changeable roles (Edwards, 2008). This fluidity makes it increasingly important to effectively manage one's interdependency with others at work, and to understand the social context of the work environment and proactively adapt to it. Such ability to be socially adaptive has been uniquely captured by the recently developed interpersonal skill concept, political skill, which encompasses a set of interrelated skills.

Politically skilled individuals are described as being socially perceptive, having a keen understanding of interpersonal dynamics, and well adapted to their social environment (Ferris et al., 2005). More specifically, politically skilled individuals are thought to be particularly strong in four areas of social life. First, these individuals are socially and self-aware and possess the capacity to form accurate perceptions of their own and others' behaviors ("social astuteness"). Second, those high in political skill have the ability to diagnose situations in ways that permit them to select the most appropriate behaviors to exhibit in order to elicit the desired responses in that situation ("interpersonal influence"). Third, political skill involves the ability to build and maintain strong social networks ("networking ability"), and, fourth, to instill rapport, trust, and goodwill into these social networks by constructing a genuine and trustworthy image of oneself (“apparent sincerity”) (Ferris et al., 2012; Ferris, Treadway et al., 2005; Ferris et al., 2007). 
In this study we focus on political skill and suggest that ERA represents a general ability that serves as the basis for the development of these skills. Research on emotional abilities and political skill has developed largely in separate literature streams and few attempts have been made to integrate the two bodies of work. To the contrary, the interrelationships among these social effectiveness constructs have mainly been studied to establish their discriminant validity or in competition with each other in terms of the predictability of performance-related outcomes (e.g., Ferris, Treadway et al., 2005; Semadar, Robins, \& Ferris, 2006). In this study, we overcome this divide by suggesting that ERA and political skill are intricately connected with each other, with ERA serving as a basic ability that allows people to develop and effectively deploy political skill. We follow the logic that emotional abilities, along with general mental abilities and personality traits, are distal antecedents of performance that exert their effect indirectly through affecting more proximate antecedents of performance (McCloy, Campbell, \& Cudeck, 1994). Amongst those proximate antecedents, we suggest, is political skill, a construct that has been demonstrated to directly affect job performance (Blickle, Kramer et al., 2011).

\section{ERA and Political Skill}

ERA is considered an important component of emotional intelligence (Mayer \& Salovey, 1997). ERA enables people to accurately perceive and interpret emotional cues. According to the emotion-as-information perspective (Forgas, 1995; Van Kleef, 2009), emotional expression serves as information to indicate an individual's inner feelings, thoughts, attitudes, and intended action. Awareness of the emotional cues of others and the ability to accurately detect and interpret these cues provides individuals with a larger, and more accurate, base of social information that helps individuals to make sense of interpersonal dynamics. Prior research found a positive link between ERA and interpersonal sensitivity (Rosenthal et al., 1979). We suggest that, besides enabling individuals to be aware of and genuinely interested in fulfilling others' 
desires and needs, ERA allows individuals to develop and apply political skill, enabling them to be strategic and effective in social interactions at work in the process of managing their interdependency with others.

Emotions are intricately related to the political power structures of social relationships (Gordon, 1990). Emotions are often used as subtle cues to convey one's social standing and the particular role or standpoint one assumes in social situations (Gordon, 1990). Indeed, prior research on the social functions of emotions suggests that emotional expression is a way for individuals to claim social status and to "mark" one's place in the pecking order of organizations (Clark, 1990). For example, the expression of anger often indicates power and status, whereas guilt and sadness reveal a lack of such qualities (Tiedens, 2001). Accurately detecting these emotions helps individuals better understand the status dynamics in social settings and identify powerful versus less powerful players, enabling individuals to position themselves well in social networks, gain important insights into an interaction partner's inner state, and effectively identify and understand others' unstated needs and intentions.

Therefore, individuals with high levels of ERA, compared to others, should be better equipped to apply political skill. They should be better able to attend to and understand the emotional signals in others behaviors. They should also be better able to adapt and choose their words, actions, and interpersonal styles in ways that allow them to appear sincere and exert influence, thus effectively building and maintaining connections with others. Over time, high ERA individuals should develop a sense of self-efficacy in navigating social situations, motivating them to engage in more social interactions and put their skills to use. This allows people to further practice and improve political skill (Ferris, Davidson, \& Perrewé, 2005), and also provides opportunities for peers to witness political skill in action. As a result, peers are likely to recognize these qualities, thus enabling individuals to establish a reputation as attentive 
and sincere colleagues able to exert influence through network connections. Therefore, we hypothesize that there should be a positive relationship between an individuals' ERA and their political skill, as assessed by peers.

Hypothesis 1: Individuals' ability to recognize emotions in others is positively related to peer-ratings of individuals' political skill.

\section{ERA and Performance}

A basic tenet of EI research is that, as a form of intelligence, it may enhance individual job performance. This proposition has been supported by some recent studies (e.g., Côté \& Miners, 2006 ; Lam \& Kirby, 2002; Lopes, Grewal, Kadis, Gall, \& Salovey, 2006; Mestre, Guil, Lopes, Salovey, \& Gil-Olarte, 2006) for the general EI construct. With regard to ERA in particular, such evidence has been gathered for decades across organizational and occupational contexts. For example, with multiple samples, Rosenthal et al. (1979) found positive relationships between ERA and peer-evaluated effectiveness among clinicians. Furthermore, Elfenbein and Ambady (2002) reported an overall positive correlation between ERA and performance evaluations by peers and supervisors of public service employees. More recently, Elfenbein and colleagues (2007) found that negotiators with high ERA not only cooperated more effectively to create value for their partners, but also competed more effectively to capture a greater proportion of the value for themselves. Positive correlations between EI and career outcomes have also been reported (e.g., Blickle, Momm et al., 2011). Building on this evidence, we contribute a more finegrained and systematic understanding of how ERA facilitates job performance and increases income.

In recent years, the global construct of individual job performance has been differentiated into job- versus interpersonal-related facets (Wildman, Bedwell, Salas, \& Smith-Jentsch, 2011). Relating to the job task itself are task performance (i.e., task proficiency) and job dedication (i.e., 
demonstrating effort and maintaining personal discipline), and relating to the interpersonal aspect is interpersonal facilitation (i.e., cooperative, considerate and helpful acts that assist coworkers' performance (Ferris, Witt, \& Hochwarter, 2001; Van Scotter \& Motowidlo, 1996). In the discussion below, we concentrate on interpersonal facilitation and how it may relate to ERA. We also consider the linkage between ERA and annual income.

\section{The Mediating Roles of Political Skill and Interpersonal Facilitation}

We suggest that, ERA will affect interpersonal facilitation. This is because ERA likely serves as the foundation of interpersonal sensitivity (Rosenthal et al., 1979). People low in ERA are less likely and will less effectively respond to others' unstated needs for assistance and support because of their lack of awareness of nonverbal cues. In contrast, people with high ERA are more likely to be sensitive to others' needs, resulting in more cooperative, considerate, and helpful acts (i.e., interpersonal facilitation).

We further suggest that the positive link between ERA and interpersonal facilitation can at least be partially explained by political skill (Ferris \& Hochwarter, 2011). Individuals high in political skill tend to be well connected with important others, and are able to build the kind of interpersonal rapport and trust needed to be positively perceived by their supervisors. Indeed, prior research suggests that people are better in interpersonal facilitation to the extent that they are politically skilled (Blickle, Kramer et al., 2011).

People high in ERA, because of their keen awareness of nonverbal cues, are more likely to develop and apply their political skill to respond to others' unstated intentions and needs, effectively gather resources from their social networks to address the need for help accordingly, and meanwhile offer this help to others in genuine and pleasant ways perceived as constructive and nonthreatening. In contrast, people with low ERA are less likely to be responsive to these 
needs, demonstrate lower political skill, and subsequently, engage in fewer helpful, facilitative actions. Thus, we propose the following:

Hypothesis 2: Peer-ratings of individuals' political skill are positively related to supervisor ratings of individuals' interpersonal facilitation.

Hypothesis 3: Peer-ratings of individuals' political skill mediate the positive relationship between individuals' emotion recognition ability and supervisor ratings of individuals' interpersonal facilitation.

But do subjective supervisor ratings of interpersonal facilitation also affect more objective job outcomes such as career success? Here we suggest that it is essential for individuals to be perceived by their supervisor as cooperative, considerate and helpful (i.e., high on interpersonal facilitation) in order to obtain well-paid positions and to advance in organizations to positions with higher salary (cf., Bouty, 2000). Indeed, individuals possessing emotional competencies are likely to draw upon these competencies to get ahead at work (Kilduff et al., 2010). ERA allows individuals to have better control over interpersonal interactions and, thus, to have greater interpersonal influence. This, in turn, helps them to occupy more central networking positions in organizations, and that, according to the career tournament theory (Turner, 1960) and social network theory (Burt, 1982), further enables them to gather resources and information necessary for career success. Therefore, it is likely that ERA enhances one's career success in terms of annual income.

Specifically, ERA, through political skills and interpersonal facilitation, should contribute to career success because individuals with these qualities should be able to better make sense of the verbal and nonverbal cues in their work environment and thus better discern and prioritize opportunities that are likely to be more rewarding in terms of tangible and intangible career outcomes. For example, perceiving a manager's enthusiasm for a certain project may prompt an 
employee with high ERA (and thus good political skill and considerable willingness to help) to take advantage of the opportunity to work on the project, the success of which is likely to enhance the employee's favorable reputation and visibility in the organization. Such strategic moves, enabled by accurate perceptions of others' emotions, politically skilled behavior, and interpersonal ease, will enhance an individual's career progression and success over time. Consistent with these assumptions, a few studies have reported a positive relationship between political skill and income (e.g., Blickle et al., 2012). Although we are not aware of any empirical study directly linking ERA with income, Byron, Terranova, and Nowicki (2007) found that salespeople who scored high on ERA earned higher annual salary raises.

\section{Hypothesis 4: Peer-ratings of individuals' political skill and supervisor ratings of individuals' interpersonal facilitation sequentially mediate the positive relationship between individuals' emotion recognition ability and individuals' objective career success measured as annual income.}

\section{METHOD}

\section{Participants and Procedure}

The study was conducted in a large industrial region in the western part of Germany. Three hundred and twenty-two employees from a broad range of jobs were personally contacted by 150 students in a psychology class. Potential participants were asked if they liked to participate in an online study on emotional abilities and if they were prepared to ask their supervisor and a peer to provide a job-related assessment of them. They were informed that confidentiality was preserved by using randomly generated codes.

All participants received three emails. The first email included a link to an online test of ERA, a personal login code, and an invitation to forward the second email to their supervisor and the third email to a peer. By the use of randomly generated codes, we were able to link 
employees' assessments with supervisors' and peers' ratings. In addition to doing the ERA test, employees reported their yearly income. Peers rated target employees' political skill, and supervisors rated target employees' job performance.

The responses were checked in two ways. First, respondents to the second and third emails were asked to report their relationship with the assessed person. The choices were subordinate, peer, supervisor, or other. We dropped all cases where the respondents were not in the prescribed roles. Second, we looked at the Internet Protocol (IP) addresses of the dyads. Responses were removed from the sample unless targets and raters had different IP addresses.

Of the 321 targets, 228 (71\%) visited the online test. Of those, 179 (79\%) completed the ERA test. A total of 168 (52\%) supervisory ratings and 172 (54\%) peer ratings were obtained. The final sample included 142 employee-peer-supervisor triads. The sample consisted of $40 \%$ males. The mean age of participants was 38 years, with a mean work experience of 16 years, and an average work time of 35.7 hours per week. Mean hierarchical position of the employees within their organizations was $45.5 \%(0 \%=$ bottom level, $100 \%=$ top level $)$.

\section{Measures}

Emotion Recognition Accuracy (ERA) was assessed with the Diagnostic Analysis of Nonverbal Accuracy (DANVA2; Nowicki \& Carton, 1993; Baum \& Nowicki, 1998). The DANVA2 test has been comprehensively validated by Nowicki and Duke (1994, 2001), and has been widely used (cf., Elfenbein \& Ambady, 2002; Nowicki, 2012). The measure contains 48 facial and vocal emotional expressions that participants are asked to identify based on photos of faces and audiotapes, respectively. The emotions of anger, fear, happiness, and sadness are represented each by six faces and six audiotapes of voices. The DANVA2 score is keyed to represent the degree to which participants' responses recognized the correct emotions. The 
overall accuracy scale ranges between 0 and 100 per cent, with a higher score indicating higher emotion recognition abilities.

To familiarize participants with the DANVA2, we provided a training prior to the test phase. This training included a trial-run of the adult version of the DANVA2 without feedback and a test-run of the children version of the DANVA2 during which participants received feedback on whether they identified the expressed emotion by the children correctly. After this familiarization phase, we administered the adult version of the DANVA2 to obtain the participants' emotion recognition scores. Cronbach's alpha was .73.

Political skill. Political skill was measured with the 18 item Political Skill Inventory (PSI - Ferris, Treadway et al., 2005). We used a validated German translation of the PSI (Blickle, Kramer et al., 2011; Lvina et al., 2012). Sample items are for social astuteness: "S/he always seems to instinctively know the right things to say or do to influence others."; interpersonal influence: "S/he is good at getting people to like him/her."; networking ability: "S/he spends a lot of time and effort at work networking with others"; apparent sincerity: "People believe s/he is sincere in what s/he says and does"). Peers rated the target individuals on a seven-point Likerttype scale and we transformed the responses to a scale ranging between 0 and 100 per cent to make it equivalent and comparable to the DANVA2 scores (cf., Muthén \& Muthén, 1998-2012). Cronbach's alpha of the composite score was .90 .

Interpersonal facilitation ratings. We used a validated German translation (Blickle, Kramer et al., 2011) of the 5-item interpersonal facilitation rating measure developed by Ferris et al. (2001). The rating anchors ranged from "a great deal better than other persons in a comparable position" to "much worse than other persons in a comparable position," with "better than," "as good as," and "worse than" as intermediate anchors. Sample items are: "This person listens carefully and responds thoughtfully in exchanging work information." Supervisors rated the 
target individuals on a scale range from 0 to 100 per cent to make it equivalent and comparable to the DANVA2 scores (cf., Muthén \& Muthén, 1998-2012). Cronbach's alpha for this measure was .82 .

Annual income. We asked individuals to report their yearly gross income based on their vocational work. Mean income was 34,314 Euro ( $S D=26,710$ Euro).

Control variables. We controlled individuals' age, gender, weekly working hours and work experience, because they are closely associated with income ( $\mathrm{Ng}$, Eby, Sorensen \& Feldman, 2005). For the same reasons, we controlled for hierarchical position $(0 \%=$ bottom level, $100 \%=$ top level) and educational level ( 1 to 6 , corresponding to the number of years in education: the lowest level was nine years of school, and the highest level was doctoral degree), as reported by the individuals. We did not control for general mental ability, because recent metaanalytic research has shown that it is not related to emotion recognition ability (Joseph \& Newman, 2011).

\section{Statistical Analyses}

The hypotheses were tested with a structural equation model using Mplus 7.1 (Muthén \& Muthén, 1998 - 2012). We created two indicators for ERA, political skill, and interpersonal facilitation: one indicator based on all odd-numbered items and the other based on all evennumbered items. This allowed us to avoid the risk of inflated goodness-of-fit statistics that arises as a result a large number of variables in the structural equation model (Herzog, Boomsma, \& Reinecke, 2007; Moshagen, 2012). Additionally, we built latent constructs for income and all control variables. Therefore, we set the variance of the single indicators to 1.00 and the error variance to .00 . To test our hypothesized mediation effects we computed bias-corrected bootstrap confidence intervals for all mediated effects with 5,000 bootstrap samples (Cheung \& Lau, 2008). Preacher, Zyphur, and Zhang (2010, p. 217, footnote 11) pointed out that mediation hypotheses 
are usually directed hypotheses and therefore to be tested on a one-tailed alpha-level of $\alpha=.05$ (corresponding to a 90\% confidence interval). Our mediation hypotheses would thus be confirmed if the $90 \%$ bias-corrected bootstrap confidence intervals $(B C-C I)$ of the computed estimates did not include zero.

Becker (2005) cautioned that control variables may hamper the analyses by unnecessarily soaking up degrees of freedom and may bias the findings related to the hypothesized variables. We therefore first analyzed the structural equation model without control variables; then, in the next step, we included all control variables and related each to the mediators and dependent variables (following recommendations by Bono \& McNamara, 2011).

\section{RESULTS}

Descriptive statistics are provided in Table 1. The correlations in Table 1 show that ERA test scores are associated with individuals' political skill $(r=.40, p<.01)$ and interpersonal facilitation $(r=.30, p<.01)$. ERA and annual income do not correlate. Furthermore, individuals' political skill relates positively with interpersonal facilitation $(r=.41, p<.01)$ and annual income $(r=.17, p<.05)$. In terms of model fit, the structural equation model (Figure 2$)$ without control variables attained an acceptable overall goodness-of-fit (Kline, 2010: $\operatorname{Chi}^{2}(12)=17.331, p=.14$, $R M S E A=0.056, S R M R=0.046, C F I=.986)$ and all estimates were significant and positive, as expected. Next, we entered the control variables; this slightly improved the positive overall model fit $\left(C h i^{2}(42)=49.546, p=.20, R M S E A=0.036, S R M R=0.047, C F I=.990\right)$.

*** Insert Table 1 and Figure 2 about here ***

Hypothesis 1 suggested that ERA relates positively to peer-rated political skill. The path coefficient was $\beta=.46(p<.01)$, thus this hypothesis was supported. Hypothesis 2 stated that peer-rated political skill relates positively to supervisor-rated interpersonal facilitation. This was supported $(\beta=.51, p<.01)$. Hypothesis 3 stated that peer-rated political skill mediates the 
relationship between ERA and supervisor-rated interpersonal facilitation. The indirect effect was significant (estimate $=.235 ; S E=.059 ; 90 \%$ BC-CI $[.119 ; .350])$. Therefore, this hypothesis was supported. In an additional analysis we modeled the path from ERA to interpersonal facilitation. The results showed that this path was not significant, revealing a full mediation.

Next we tested whether ERA was linked to annual income as an objective indicator of career success (Hypothesis 4) through the sequential mediation of peer-rated political skill and supervisor-rated interpersonal facilitation. The path coefficient of interpersonal facilitation on income was $\beta=.15(p<.01)$ and the indirect effect was significant (estimate $=.035 ; S E=.019$; 90\% BC-CI [.003; .066]), supporting our Hypothesis 4.

\section{DISCUSSION}

In this study, we investigated how the ability to recognize others' emotions (ERA) translates into favorable work-related outcomes. Integrating social influence and emotional intelligence research, we disentangled the relationships between ERA, political skill, and job performance and career success. We hypothesized that people with high levels of ERA have better political skills that directly facilitate interpersonal interaction and indirectly (through interpersonal facilitation) allow them to receive higher annual incomes than people with low levels of ERA. In a sample of German employees with diverse occupations and jobs, and even when controlling for the effects of age, gender, educational level, weekly work hours, work experience, and hierarchical position, we found support for our theoretical model that ERA is linked to annual income through political skill and interpersonal facilitation.

\section{Theoretical Implications}

The theory and findings contribute in several ways to the emotion and the social influence literatures. First, our results give further support to the central proposition in the emotional intelligence literature that emotion-related abilities enhance human performance at work. We 
focused specifically on ERA, a dimension of emotional intelligence, and we found that this very basic ability has effects on the interpersonal facilitation facet of job performance and, most notably, even on annual income, an objective indicator of career success. The better people are at recognizing emotions, the better they handle the politics in organizations and the interpersonal aspects of work life, and thus the more they earn in their jobs.

Second, we found that political skill functioned as an intermediate mechanism to explain the performance-enhancing effect of ERA. Prior research based on the notion that emotional intelligence is one form of intelligence - and as such a distal predictor of performance suggested that emotional intelligence enhances job performance because of individuals' enhanced ability to handle affective-laden information at work. Our research shows that being emotionally intelligent also helps individuals effectively apply political skill. Such proximate skill is then used by individuals high in emotional intelligence to facilitate their performance and career outcomes by influencing others socially. This is important because it reinforces the idea that organizations function as political arenas in which individuals use their emotional and social competencies not only directly to deliver better performance per se, but also indirectly to manage their social environment at work, gain power and popularity, and achieve their personal goals thus increasing their chances of being seen as high performers and advancing in their careers.

Third, our study sheds light on the interrelationships among various social effectiveness constructs. Both the emotion and social influence literature have attracted a remarkable amount of scholarly interest in recent years and two social effectiveness constructs, emotional intelligence and political skill, have been at the center of attention. Emotional intelligence and political skill share some conceptual overlap (Ferris et al., 2002; Liu et al., 2006). Both are social competency variables, both entail the ability to skillfully navigate one's social environment and similarly, both have been found to play significant roles in performance and career outcomes 
(e.g., Côté \& Miners, 2006; Harris, Kacmar, Zivnuska, \& Shaw, 2007; Perrewé, Zellars, Ferris, Rossi, Kacmar, \& Ralston, 2004; Treadway, Ferris, Duke, Adams, \& Thatcher, 2007). But their interconnection has remained neglected. The present findings show that ERA is a distal basic ability that facilitates the application of political skill as a proximate capability to advance job performance and career success.

\section{Practical Implications}

Because of the performance-enhancing potential of emotional intelligence, practitioners have been interested in using it for selection and training purposes from the very beginning of the popularization of the construct. The results of our study suggest that this interest is legitimate. For managers and employees who aspire to perform well and have successful careers, our study suggests that cultivating abilities and skills such as ERA and political skill is beneficial. In organizations, individuals come together, become dependent upon each other, and co-experience the consequences of each other's behaviors. An organization's success critically depends on the ability of its members to coordinate and cooperate well with each other. Interpersonal skills enable the development of a more congenial social environment created by individuals' enhanced abilities to process nonverbal cues, to understand each other's inner states, and to behave according to socially negotiated norms and mutual expectations. Individuals equipped with such skills are therefore more likely to be well received by others, gain power and influence, and get ahead. The findings of the present study extend the previous meta-analytic findings of Higgins et al. (2003) on the use of social influence tactics at work.

A note of caution is in order regarding the potential "dark side" of ERA and political skill for organizations (cf. Kilduff et al., 2010). Because individuals have the freedom to use their emotional and political skills to benefit either themselves or their organizations (or both), it is necessary for organizations to set boundaries in terms of organizational structures, practices and 
procedures, so a climate emerges that encourages and rewards the ethical use of such talents and skills, but prevents and punishes other uses. If employees perceive that the workplace is just and equitable, it is less likely that they will use their skills to the advantage themselves at the expense of others or of the organization they are meant to serve.

\section{Limitations and Future Research Directions}

This study focused on only one dimension of emotional intelligence - ERA. We did not explore how other dimensions that include abilities to understand and manage emotions relate with political skill and, in turn, performance and career outcomes. It is likely that other emotional abilities also benefit people's social astuteness, interpersonal influence, networking ability, and apparent sincerity. Therefore, future research may examine how emotional intelligence more broadly links with political skill and how the dimensions of each construct relate with one another to bring about performance effects.

Our study was conducted with a sample consisting of people in diverse jobs and different organizations. Therefore, the findings are not confined to a specific setting but rather generalize across jobs and organizations. A closer look at the types of jobs and organizations would still be desirable in future research. Some jobs and organizations may require more political skills than others - for example, jobs with few objective performance indicators and organizations emphasizing social interaction. Therefore, in these jobs and organizations, compared to others, people should benefit to a larger extent from ERA.

More broadly, this research raises further questions about how people use their emotional abilities in the double challenge of getting along and getting ahead at work. Our research reveals that ERA allows people to act more politically skilled in the social environment of organizations and thus to yield benefits for themselves in the form of better job performance ratings from supervisors and higher income. We conclude that individuals benefit from emotional abilities and 
political skill - but will organizations benefit as well? It remains an open question whether and when people apply their emotional abilities and political skill in the pursuit of self-interests rather than organizational interests. Further work is necessary to identify the boundary conditions that ensure that people engage their emotional abilities and political skill not only for their own progress, but also for the benefit of others and the organization as a whole.

\section{Conclusion}

This study shed light on the intermediary mechanism explaining why ERA is linked to job performance and career success. We found that emotional abilities are not only applied at work to process affect-laden information and deal with emotionally challenging situations, but also in the pursuit of interpersonal influence, reputation management, and networking. It is in part through these political skills, we discovered, that emotionally perceptive people gain benefits at work. If our study has one overriding message, it is that seeing what others feel and using this information to navigate through the social world of organizations helps making people successful at work. 


\section{REFERENCES}

Baum, K., \& Nowicki, S. 1998. Perception of emotion: Measuring decoding accuracy of adult prosodic cues varying in intensity. Journal of Nonverbal Behavior, 22: 89-109.

Becker, T. E. 2005. Potential problems in the statistical control of variables in organizational research: A qualitative analysis with recommendations. Organizational Research Methods, 8: 274-289.

Blickle, G., Kramer, J., Schneider, P. B., Meurs, J. A., Ferris, G. R., Mierke, J., Witzki, A. H. \& Momm, T. D. 2011. Role of political skill in job performance prediction beyond general mental ability and personality in cross-sectional and predictive studies. Journal of Applied Social Psychology, 41: 488-514.

Blickle, G., Momm, T. D., \& Liu, Y., Witzki, A., \& Steinmayr, R. 2011. Construct validation of the Test of Emotional Intelligence (TEMINT): A two-study investigation. European Journal of Psychological Assessment, 27: 282-289.

Bono, J. E., \& McNamara, G. 2011. Publishing in AMJ - Part 2: Research design. Academy of Management Journal, 54: 657-660.

Bouty, I. 2000. Interpersonal and interaction influences on informal resource exchanges between R\&D researchers across organizational boundaries. Academy of Management Journal, 43: $50-65$.

Burns, T. 1962. Micropolitics: Mechanicsm of institutional change. Administrative Science Quarterly, 6: 257-281.

Burt, R. S. 1982. Toward a structural theory of action. New York: Academic Press.

Byron, K., Terranova, S., \& Nowicki, S. 2007. Nonverbal emotion recognition and salespersons: Linking ability to perceived and actual success. Journal of Applied Social Psychology, 37: 2600-2619. 
Cascio, W. F. 1995. Whither industrial and organizational psychology in a changing world of work. American Psychologist, 50: 928-939.

Cheung, G. W. \& Lau, R. S. 2008. Testing mediation and suppression effects of latent variables: Bootstrapping with structural equation models. Organizational Research Methods, 11: 296-325.

Clark, C. 1990. Emotions and micropolitics in everyday life: Some patterns and paradoxes of “place.” In T. D. Kemper (Ed.), Research agendas in the sociology of emotions (pp. 305333). Albany, NY: State University of New York Press.

Côté, S., \& Miners, C. T. H. 2006. Emotional intelligence, cognitive intelligence, and job performance. Administrative Science Quarterly, 51: 1-28.

Daft, R. L., \& Lewin, A. Y. 1993. Where are the theories for the "new" organizational forms? An editorial essay. Organization Science, 4: i-vi.

Edwards, J. R. 2008. Person-environment fit in organizations: An assessment of theoretical progress. Academy of Management Annals, 2: 167-230.

Elfenbein, H. A., \& Ambady, N. 2002. Predicting workplace outcomes from the ability to eavesdrop on feelings. Journal of Applied Psychology, 87: 963-971.

Elfenbein, H. A., Foo, M. D., White, J., Tan, H. H., \& Aik, V. C. 2007. Reading your counterpart: The benefit of emotion recognition accuracy for effectiveness in negotiation. Journal of Nonverbal Behavior, 31: 205-223.

Elfenbein, H. A., Marsh, A. A., \& Ambady, N. 2002. Emotional intelligence and the recognition of emotion from facial expressions. In L. F. Barrett, \& P. Salovey (Eds.), The wisdom in feeling: Psychological processes in emotional intelligence (pp. 37-59). New York:

Guilford Press. 
Ferris, G. R., Davidson, S. L., \& Perrewé, P. L. 2005. Political skill at work: Impact on work effectiveness. Mountain View, CA: Davies-Black Publishing.

Ferris, G. R., Treadway, D. C., Kolodinsky, R. W., Hochwarter, W. A., Kacmar, C. J., Douglas, C., \& Frink, D. D. 2005. Development and validation of the political skill inventory. Journal of Management, 31: 126-152.

Ferris, G. R., Witt, L. A., \& Hochwarter, W. A. 2001. Interaction of social skill and general mental ability on job performance and salary. Journal of Applied Psychology, 86: 10751082.

Ferris, G. R., Hochwarter, W. A., Douglas, C., Blass, R., Kolodinsky, R. W., \& Treadway, D. C. 2002. Social influence processes in organizations and human resources systems. In G. R. Ferris \& J. J. Martocchio (Eds.), Research in personnel and human resources management (Vol. 21, pp. 65-127). Oxford, UK: JAI Press/Elsevier Science.

Forgas, J. P. 1995. Mood and judgment: The Affect Infusion Model (AIM). Psychological Bulletin, 117: 39-66.

Gordon, S. L. 1990. Social structural effects on emotions. In T. D. Kemper (Ed.), Research agendas in the sociology of emotions (pp. 145-179). Albany, NY: State University of New York Press.

Harris, K. J., Kacmar, K. M., Zivnuska, S., \& Shaw, J. D. 2007. The impact of political skill on impression management effectiveness. Journal of Applied Psychology, 92: 278-285.

Herzog, W., Boomsma, A., \& Reinecke, S. 2007. The model-size effect on traditional and modified tests of covariance structures. Structural Equation Modeling, 14: 361-390.

Higgins, C. A., Judge, T. A., \& Ferris, G. R. 2003. Influence tactics and work outcomes: A metaanalysis. Journal of Organizational Behavior, 24: 89-106. 
Hogan, R., \& Shelton. D. 1998. A socioanalytic perspective on job performance. Human Performance, 11: 129-144.

Joseph, D. L., \& Newman, D. A. 2010. Emotional intelligence: An integrative meta-analysis and cascading model. Journal of Applied Psychology, 95: 54-78.

Kilduff, M., Chiaburu, D. S., \& Menges, J. I. 2010. Strategic use of emotional intelligence in organizational settings: Exploring the dark side. Research in Organizational Behavior, 30: 129-152.

Kline, R. B. 2010. Principles and practice of structural equation modeling. New York: Guilford Press.

Lam, L. T., \& Kirby, S. L. 2002. Is emotional intelligence an advantage? An exploration of the impact of emotional and general intelligence on individual performance. Journal of Social Psychology, 142: 133-143.

Lvina, E., Johns, G., Treadway, D. C., Blickle, G., Liu, Y., Liu, J., Atay, S., Zettler, I., Solga, J., Noethen, D., \& Ferris, G.R. 2012. Measure invariance of the Political Skill Inventory (PSI) across five cultures. International Journal of Cross-Cultural Management, 12: 171-191.

Lopes, P. N., Grewal, D., Kadis, J., Gall, M., \& Salovey, P. 2006. Evidence that emotional intelligence is related to job performance and affect and attitudes at work. Psicothema, 18: $132-138$.

Liu, Y., Ferris, G. R., Treadway, D. C., Prati, L. M., Hochwarter, W. A., \& Perrewé, P. L. 2006. The emotion of politics and the politics of emotions: Affective and cognitive reactions to politics as a stressor. In E. Vigoda-Gadot \& A. Drory (Eds.), Handbook of organizational politics (pp. 161-186). Northampton, MA: Edward Elgar Publishing. 
Mayer, J. D., \& Salovey, P. 1997. What is emotional intelligence? In P. Salovey \& D. Sluyter (Eds.), Emotional development and emotional intelligence: Implications for educators (pp. 3-31). New York: Basic Books.

McCloy, R. A., Campbell, J. P., \& Cudeck, R. 1994. A confirmatory test of a model of performance determinants. Journal of Applied Psychology, 79, 493-505.

Mestre, J.M., Guil, R., Lopes, P., Salovey, P., \& Gil-Olarte, P. 2006. Emotional intelligence and social and academic adaptation to school. Psicothema, 18: 112-117.

Moshagen, M. 2012. The model size effect in SEM: Inflated goodness-of-fit statistics are due to the size of the covariance matrix. Structural Equation Modeling, 19: 86-98.

Muthén, L. K., \& Muthén, B. O. 1998-2012. Mplus user's guide (7th ed.). Los Angeles, Ca: Muthén \& Muthén.

Ng, T. W. H., Eby, L., Sorensen, K. L., \& Feldman, D. C. 2005. Predictors of objective and subjective career success: A meta-analysis. Personnel Psychology, 58: 367-408.

Nowicki, S. 2012. A manual for the Diagnostic Analysis of Nonverbal Accuracy. Unpublished manuscript. Department of Psychology, Emory University, Atlanta, GA.

Nowicki, S., \& Carton, J. 1993. The measurement of emotional intensity from facial expressions: The DANVA FACES 2. Journal of Social Psychology, 133: 749-750.

Nowicki, S., \& Duke, M. P. 1994. Individual differences in the nonverbal communication of affect: The Diagnostic Analysis of Nonverbal Accuracy Scale. Journal of Nonverbal Behavior, 18: 9-35.

Nowicki, S., \& Duke, M. P. 2001. Nonverbal receptivity: The Diagnostic Analysis of Nonverbal Accuracy (DANVA). In J. A. Hall \& F. J. Bernieri (Eds.), Interpersonal sensitivity: Theory and measurement (pp. 183-198). Mahwah, NJ: Erlbaum. 
Perrewé, P., Zellars, K., Ferris, G., Rossi, A., Kacmar, C., \& Ralston, D. 2004. Neutralizing job stressors: Political skill as an antidote to the dysfunctional consequences of role conflict stressors. Academy of Management Journal, 47: 141-152.

Preacher, K. J., Zyphur, M. J., \& Zhang, Z. 2010. A general multilevel SEM framework for assessing multilevel mediation. Psychological Methods, 15: 209-233.

Rosenthal, R., Hall, J., DiMatteo, M. R., Rogers, P. L., \& Archer, D. 1979. Sensitivity to nonverbal communication: The PONS test. Baltimore, MD: John Hopkins University Press.

Semadar, A., Robins, G., \& Ferris, G. R. 2006. Comparing the effects of multiple social effectiveness constructs in the prediction of managerial performance. Journal of Organizational Behavior, 27: 443-461.

Seibert, S. E., Kraimer, M. L., \& Liden, R. C. 2001. A social capital theory of career success. Academy of Management Journal, 44: 219-237.

Tiedens, L. Z. 2001. Anger and advancement versus sadness and subjugation: The effect of negative emotion expressions on social status conferral. Journal of Personality and Social Psychology, 80: 86-94.

Treadway, D., Ferris, G., Duke, A., Adams, G., \& Thatcher, J. 2007. The moderating role of subordinate political skill on supervisors' impressions of subordinate ingratiation and ratings of interpersonal facilitation. Journal of Applied Psychology, 92: 848-855.

Turner, R. J. 1960. Sponsored and contest mobility and the school system. American Sociological Review, 25: 855-867.

Van Kleef, G. A. 2009. How emotions regulate social life: The Emotions as Social Information (EASI) model. Current Directions in Psychological Science, 18 : 184-188. 
Van Scotter, J. R., \& Motowidlo, S. J. 1996. Interpersonal facilitation and job dedication as separate facets of contextual performance. Journal of Applied Psychology, 81: 525-531.

Wildman, J. L., Bedwell, W. L., Salas, E. \& Smith-Jentsch, K. 2011. Performance measurement at work: A multilevel perspective. In S. Zedeck (Ed.), APA handbook of industrial and organizational psychology (Vol. 1, pp. 303-341). Washington, DC: American Psychological Association. 
TABLE 1

MEANS, STANDARD DEVIATIONS, RELIABILITIES, AND CORRELATIONS OF STUDY VARIABLES

\begin{tabular}{|c|c|c|c|c|c|c|c|c|c|c|c|}
\hline Variables & $M$ & $S D$ & 1 & 2 & 3 & 4 & 5 & 6 & 7 & 8 & 9 \\
\hline 1. Gender ${ }^{\mathrm{a}}$ & .60 & .49 & & & & & & & & & \\
\hline 2. Age & 38.21 & 12.64 & .02 & & & & & & & & \\
\hline 3. Weekly working hours & 35.73 & 8.19 & -.11 & .06 & & & & & & & \\
\hline 4. Years of work experience & 16.04 & 12.80 & -.04 & $.92 * *$ & .10 & & & & & & \\
\hline 5. Hierarchical position & 45.54 & 20.30 & $-.18 *$ & $.36 * *$ & $.29 * *$ & $.36^{* *}$ & & & & & \\
\hline 6. Educational level & 3.70 & 1.10 & .09 & $.18^{*}$ & $.22 * *$ & .08 & .14 & & & & \\
\hline $\begin{array}{l}\text { 7. Emotion recognition ability (tested with } \\
\text { DANVA2) }\end{array}$ & 77.23 & 10.37 & -.04 & $-.19 *$ & .01 & $-.17 *$ & -.11 & .12 & $(.73)$ & & \\
\hline 8. Political skill (rated by peers) & 65.88 & 12.53 & -.01 & -.05 & .04 & -.01 & -.05 & $.17 *$ & $.40 * *$ & $(.90)$ & \\
\hline $\begin{array}{l}\text { 9. Interpersonal facilitation (rated by } \\
\text { supervisors) }\end{array}$ & 72.88 & 15.77 & -.14 & -.08 & .07 & -.02 & -.01 & .04 & $.30 * *$ & $.41 * *$ & $(.82)$ \\
\hline 10. Employees' yearly income (in Euro) & 34,314 & 26,710 & $-.30 * *$ & $.40 * *$ & $.32 * *$ & $.36^{* *}$ & $.38 * *$ & $.36^{* *}$ & .05 & $.17 *$ & .14 \\
\hline
\end{tabular}

Note. $N=142$; Cronbach's Alphas in the diagonal; ${ }^{a}$ Gender is coded $0=$ male, $1=$ female;

$* p<.05 ;$

$* * p<.01$. 


\section{FIGURE 1}

THE THEORETICAL MODEL

\begin{tabular}{|c|c|c|c|}
\hline $\begin{array}{c}\text { Emotion Recognition } \\
\text { Ability } \\
\text { (tested with DANVA2) }\end{array}$ & $\begin{array}{l}\text { Political Skill } \\
\text { (rated by peers) }\end{array}$ & $\begin{array}{c}\text { Interpersonal } \\
\text { Facilitation } \\
\text { (rated by supervisors) }\end{array}$ & $\begin{array}{c}\text { Career Success } \\
\text { (measured as annual } \\
\text { income in Euro) }\end{array}$ \\
\hline
\end{tabular}

Note. DANVA2 (Diagnostic Analysis of Nonverbal Accuracy; Nowicki \& Duke, 1994). 


\section{FIGURE 2}

\section{STRUCTURAL EQUATION MODEL}

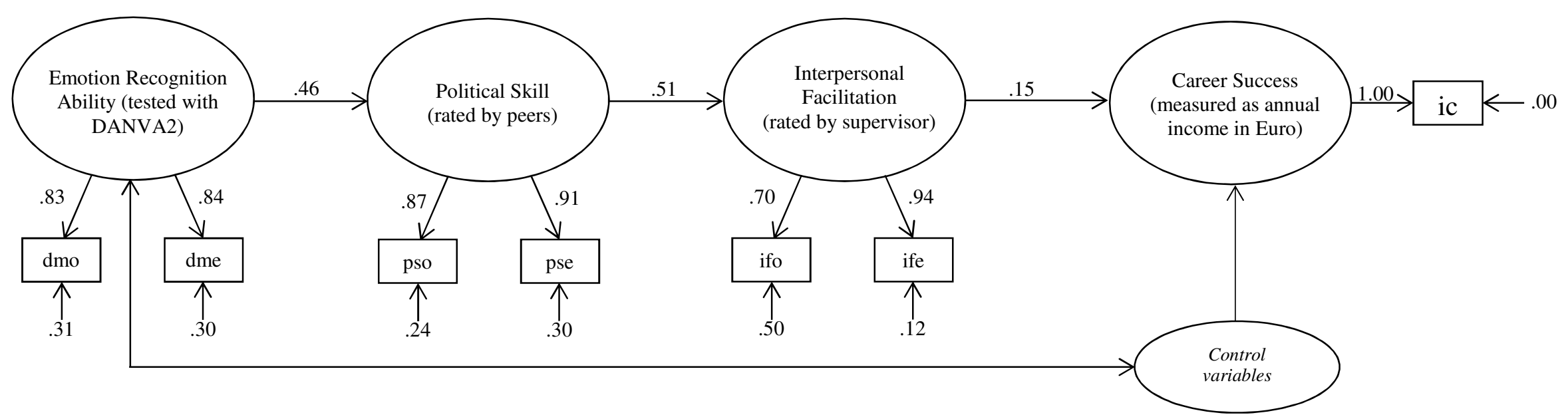

Note. $N=142$ triples of targets, peers, and supervisors; Overall model fit: $C h i^{2}(42)=49.546, p=.20, R M S E A=0.036, S R M R=0.047, C F I=.990$; do = DANVA2 based on odd-numbered items (1, 3, etc.), de = DANVA2 based on even-numbered items (2, 4, etc.); pso = political skill based on odd-numbered items, pse = political skill based on even-numbered items, ifo = interpersonal facilitation based on based on odd-numbered items, ife = interpersonal facilitation based on based on even-numbered items, ic = income, control variables: age, gender, working hours, working experience, hierarchical position, educational level, all control variable indicators had a variance of 1.00 and an error variance of .00; all path estimates and construct indicators above .14 are significant at $p<.05$; all path estimates and construct indicators above .23 are significant at $p<.01$. 